\title{
The myocardial protective effects of a moderate-potassium adenosine-lidocaine cardioplegia in pediatric cardiac surgery
}

\author{
Zhen-Xiao Jin, MD, PhD, ${ }^{\mathrm{a}, *}$ Sheng-Li Zhang, MD, ${ }^{\mathrm{a}, *}$ Xi-Ming Wang, MD, ${ }^{\text {a }}$ Sheng-Hui Bi, MD, ${ }^{\mathrm{a}}$ Mei Xin, MD, ${ }^{\mathrm{a}}$ \\ Jing-Jun Zhou, PhD, ${ }^{\mathrm{b}}$ Qin Cui, MD, PhD, ${ }^{\mathrm{a}}$ Wei-Xun Duan, MD, PhD, ${ }^{\mathrm{a}}$ Hong-Bing Wang, MD, and Ding-Hua Yi, MD, PhD ${ }^{\mathrm{a}}$
}

\begin{abstract}
Objectives: We sought to evaluate a moderate-potassium cardioplegic solution using adenosine and lidocaine as the arresting and protecting cardioprotective combination in pediatric cardiac surgery.

Methods: One hundred thirty-four patients with congenital heart disease were randomly allocated to one of 3 groups according to the cardioplegia formula used: the high-potassium (HP) group ( $\left.\mathrm{K}^{+}, 20 \mathrm{mmol} / \mathrm{L}\right), 46 \mathrm{patients}$; the high-potassium adenosine-lidocaine (HPAL) group $\left(\mathrm{K}^{+}, 20 \mathrm{mmol} / \mathrm{L}\right.$; adenosine, $0.7 \mathrm{mmol} / \mathrm{L}$; and lidocaine, $0.7 \mathrm{mmol} / \mathrm{L}), 44$ patients; and the moderate-potassium adenosine-lidocaine (MPAL) group $\left(\mathrm{K}^{+}, 10 \mathrm{mmol} / \mathrm{L}\right.$; adenosine, $0.7 \mathrm{mmol} / \mathrm{L}$; and lidocaine, $0.7 \mathrm{mmol} / \mathrm{L}$ ), 44 patients. Hemodynamic data during the operation and postoperative data were recorded. Serum cardiac troponin I concentrations were examined at the time points of before cardiopulmonary bypass and 1, 3, 6, 12, and 24 hours after aortic crossclamp removal.
\end{abstract}

Results: At the end of cardiopulmonary bypass and modified ultrafiltration, the systolic and pulse pressures of the MPAL group were significantly increased compared with the respective values of the HP group. At the time points of 1 to 12 hours after reperfusion, the levels of serum cardiac troponin I were significantly decreased in the MPAL group compared with those in the HP and HPAL groups.

Conclusions: The MPAL cardioplegia formula was associated with better myocardial protective effects.

Currently, the majority of cardiac surgery centers use a highpotassium cardioplegic solution to arrest the heart during cardiac operations. The concentration of potassium is typically greater than $15 \mathrm{mmol} / \mathrm{L}^{1}$ Yet some studies have demonstrated that high-potassium cardioplegia can induce myocardial ionic and metabolic imbalances during ischemia and myocardial stunning, tissue edema, endothelial damage, free radical production, and functional loss during reperfusion. ${ }^{2}$

An alternative approach to arresting the heart is to maintain the transmembrane electrical potential in a polarized state ${ }^{3}$ which locks the ion channels in a "closed" state. Therefore ionic imbalances and subsequent consequences are likely to be avoided. ${ }^{3}$ Adenosine triphosphate-sensitive potassium channel-opening agents (eg, nicorandil and aprikalim) have been used to achieve polarized or hyperpolarized arrest. $^{2}$ However, potassium channel-opening agents have been reported to increase postischemic arrhythmias and myocardial oxygen demand on reperfusion and to produce profound systemic hypotension. For these reasons, hy-

From the Institute of Cardiovascular Surgery, ${ }^{a}$ Xijing Hospital and the Department of Physiology, ${ }^{\mathrm{b}}$ the Fourth Military Medical University, Xi'an, China.

Supported by the National 11th Five-year Science and Technology Supporting Project of China (2006BAI01A08) and Shaanxi Province Science and Technology Fund (2007K14-05[10]) and (2006K13-G1[2]).

* Drs Jin and Zhang contributed equally to this article.

Received for publication Jan 14, 2008; revisions received Feb 22, 2008; accepted for publication March 20, 2008.

Address for reprints: Ding-Hua Yi, MD, PhD, Institute of Cardiovascular Surgery, Xijing Hospital, the Fourth Military Medical University, 17 Changle West Rd,

Xi'an, China (E-mail: yidinghua@yahoo.com.cn).

J Thorac Cardiovasc Surg 2008;136:1450-5

$0022-5223 / \$ 34.00$

Copyright (c) 2008 by The American Association for Thoracic Surgery

doi:10.1016/j.jtcvs.2008.03.025 perpolarized arrest with a potassium channel-opening agent as the arresting agent has not been adopted as a clinical cardioplegic strategy.

The combination of adenosine and lidocaine is an alternative method to achieve polarized arrest. ${ }^{4}$ In 2004 , Corvera and colleagues ${ }^{4}$ reported the effects of normokalemic adenosine-lidocaine (AL) cardioplegia on an isolated rat heart perfusion model. The AL cardioplegia was based on Krebs-Henseleit solution, which contained $0.2 \mathrm{mmol} / \mathrm{L}$ adenosine and $5 \mathrm{mmol} / \mathrm{L}$ lidocaine and in which the potassium concentration was $5.9 \mathrm{mmol} / \mathrm{L}$. The theory underlying the experiment was that this normokalemic AL cardioplegia solution could arrest the heart and meanwhile maintain the myocardial cell membrane potential at the normal level (about $-83 \mathrm{mV}$ ), which might avoid ion-channel activation and extra energy consumption and in turn might improve a protective effect. In 2005, Corvera and associates ${ }^{5}$ reported their in vivo experimental study on a canine cardiopulmonary bypass (CPB) model, which demonstrated that the myocardial protective effects of warm or cold $\mathrm{AL}$ blood cardioplegia were equivalent to those of hypothermic potassium blood cardioplegia. The aim of this study was to investigate the cardioprotective effect of moderate-potassium AL cardioplegia in the clinical setting of pediatric cardiac surgery.

\section{MATERIALS AND METHODS}

The study was performed according to the Declaration of Helsinki (revised version of Somerset West, Republic of South Africa, 1996) and all relevant Chinese laws. The study protocol was approved by the ethics committee of Xijing Hospital. All subjects provided written informed consent before inclusion in the study. 


$$
\begin{aligned}
& \text { Abbreviations and Acronyms } \\
& \begin{aligned}
\text { AL } & =\text { adenosine-lidocaine } \\
\text { CPB } & =\text { cardiopulmonary bypass } \\
\text { cTnI } & =\text { cardiac troponin I } \\
\text { HP } & =\text { high potassium } \\
\text { HPAL } & =\text { high-potassium adenosine-lidocaine } \\
\text { ICU } & =\text { intensive care unit } \\
\text { MPAL } & =\text { moderate-potassium adenosine-lidocaine } \\
\text { MUF } & =\text { modified ultrafiltration } \\
\text { PRBC } & =\text { packed red blood cell }
\end{aligned}
\end{aligned}
$$

\section{Composition of Cardioplegic Solutions}

The basic cardioplegic solution was supplied by the clinical pharmacy of Xijing Hospital; $10 \% \mathrm{KCl}$ solution, $2 \%$ lidocaine solution, and $0.3 \%$ adenosine solution were added before use by the perfusionist to achieve the various cardioplegic formulas. The compositions of the cardioplegic solutions are as follows:

- high-potassium (HP) cardioplegia: $\mathrm{Na}^{+}, 117 \mathrm{mmol} / \mathrm{L} ; \mathrm{K}^{+}, 20.0 \mathrm{mmol} / \mathrm{L}$; $\mathrm{Mg}^{++}, 16 \mathrm{mmol} / \mathrm{L} ; \mathrm{Ca}^{++}, 1.2 \mathrm{mmol} / \mathrm{L} ; \mathrm{HCO}_{3}^{-}, 25 \mathrm{mmol} / \mathrm{L}, \mathrm{Cl}, 140 \mathrm{mmol} /$ $\mathrm{L}$; glucose, $10 \mathrm{mmol} / \mathrm{L} ; \mathrm{pH} 7.48$;

- high-potassium AL (HPAL) cardioplegia: $\mathrm{Na}^{+}, 117 \mathrm{mmol} / \mathrm{L} ; \mathrm{K}^{+}, 20.0$ $\mathrm{mmol} / \mathrm{L} ; \mathrm{Mg}^{++}, 16 \mathrm{mmol} / \mathrm{L} ; \mathrm{Ca}^{++}, 1.2 \mathrm{mmol} / \mathrm{L} ; \mathrm{HCO}_{3}^{-}, 25 \mathrm{mmol} / \mathrm{L}$; $\mathrm{Cl}^{-}, 140 \mathrm{mmol} / \mathrm{L}$; glucose, $10 \mathrm{mmol} / \mathrm{L}$; lidocaine, $0.7 \mathrm{mmol} / \mathrm{L}$; adenosine, $0.7 \mathrm{mmol} / \mathrm{L} ; \mathrm{pH} 7.48$; and

- moderate-potassium AL (MPAL) cardioplegia: $\mathrm{Na}^{+}, 117 \mathrm{mmol} / \mathrm{L} ; \mathrm{K}^{+}$, $10.0 \mathrm{mmol} / \mathrm{L} ; \mathrm{Mg}^{++}, 16 \mathrm{mmol} / \mathrm{L} ; \mathrm{Ca}^{++}, 1.2 \mathrm{mmol} / \mathrm{L} ; \mathrm{HCO}_{3}^{-}, 25 \mathrm{mmol} /$ $\mathrm{L} ; \mathrm{Cl}^{-}, 140 \mathrm{mmol} / \mathrm{L}$; glucose, $10 \mathrm{mmol} / \mathrm{L}$; lidocaine, $0.7 \mathrm{mmol} / \mathrm{L}$; adenosine, $0.7 \mathrm{mmol} / \mathrm{L} ; \mathrm{pH} 7.48$.

\section{Experimental Design}

We performed a prospective, single-center, randomized controlled study. After patients provided informed consent, they were randomly allocated either to the HP cardioplegia group, the HPAL cardioplegia group, or the MPAL cardioplegia group. The randomization was realized by messages sealed in envelopes passed to the perfusionist just before the operation, with the surgeons and intensive care physicians being unaware of the allocation.

\section{Study Population}

Patients given diagnoses of congenital heart disease for which a clinical decision was made to treat with a cardiac operation were eligible for enrollment. Patients who were cocommitted with other systemic diseases or reoperation or had undergone right or left ventricular incision were not included. One hundred thirty-four patients who were admitted in the institute of cardiovascular surgery, Xijing Hospital, between March 1, 2007, and May 31, 2007 , were included in the present study. Table 1 summarizes the primary characteristics of the study population. There were no significant differences among the 3 groups with regard to age, sex, and body weight or defect types. The ratio of concomitant pulmonary hypertension among the 3 groups was also comparable, which indicated that the randomized allocation of the patients into 3 study groups was successful.

\section{Anesthesia, CPB, and Surgical Intervention}

Anesthesia, CPB, and surgical intervention were performed by the same group of cardiac surgeons, perfusionists, and anesthetists. Anesthesia was induced and maintained with intravenous propofol (target-controlled infusion), sufentanil citrate, and atracurium. Patients' blood was heparinized
TABLE 1. Characteristics and congenital heart defect distributions among the 3 groups

\begin{tabular}{lcccc}
\hline & $\begin{array}{c}\text { HP group } \\
(\mathbf{n}=\mathbf{4 6})\end{array}$ & $\begin{array}{c}\text { HPAL group } \\
(\mathbf{n}=\mathbf{4 4})\end{array}$ & $\begin{array}{c}\text { MPAL group } \\
(\mathbf{n}=\mathbf{4 4})\end{array}$ & $\begin{array}{c}\boldsymbol{P} \\
\text { value }\end{array}$ \\
\hline Sex, F/M & $12 / 34$ & $18 / 26$ & $16 / 28$ & NS \\
Age, mo & $23.3 \pm 2.8$ & $25.1 \pm 2.9$ & $24.2 \pm 3.2$ & .911 \\
Body weight, kg & $10.0 \pm 0.6$ & $10.0 \pm 0.5$ & $9.9 \pm 0.5$ & .992 \\
Diagnosis, $\mathrm{n}$ & & & & \\
ASD & 0 & 6 & 0 & \\
CAVCD & 0 & 2 & 0 & \\
MI & 2 & 0 & 0 & \\
PAVCD & 2 & 0 & 2 & \\
TAPVC+ASD & 2 & 0 & 4 & \\
VSD & 40 & 36 & 38 & NS \\
VSD & 30 & 30 & 26 & \\
VSD+AI & 2 & 0 & 0 & \\
VSD + ASD & 2 & 6 & 6 & \\
VSD+MI & 4 & 0 & 2 & \\
VSD + PDA & 2 & 0 & 4 & \\
Concomitant PH & 28 & 26 & 24 & NS \\
\hline
\end{tabular}

$H P$, High potassium; $H P A L$, high potassium adenosine-lidocaine; $M P A L$, moderatepotassium adenosine-lidocaine; $A S D$, atrial septal defect; $C A V C D$, complete atrial ventricle canal defect; $M I$, mitral valve insufficiency; $P A V C D$, partial atrial ventricle canal defect; $T A P V C$, total anomalous pulmonary vein connection; $V S D$, ventricular septal defect; $A I$, aortic valve insufficiency; $P D A$, patent ductus arteriosus; $P H$, pulmonary arterial hypertension.

before $\mathrm{CPB}$ with $300 \mathrm{IU} / \mathrm{kg}$ heparin, and the activated clotting time was maintained during CPB at a value greater than 480 seconds by using kaolin as the activating agent (ACT II HemoTec; Medtronic, Rueil Malmaison, France), with additional doses of heparin, as required. The CPB was set up with aortic cannulation and superior and inferior vena caval cannulation. The extracorporeal circuit was primed with various amounts of a balanced acetate solution containing $5 \%$ albumin, $0.5 \mathrm{~g} / \mathrm{kg}$ mannitol, $2500 \mathrm{U}$ of heparin, and $1 \times 10^{6} \mathrm{KIU}$ aprotinin. Packed red blood cells (PRBCs) were added to the priming solution to maintain the CPB hematocrit value at approximately 0.25 , and an appropriate volume of $5 \% \mathrm{NaHCO}_{3}$ was added to correct the $\mathrm{pH}$ of the priming solution to 7.35 to 7.40. No calcium was added to the priming solution. A membrane oxygenator was used, and the appropriate flows were obtained with a roller pump (Stockert Instruments, Munich, Germany) during moderate hypothermia (esophageal temperature, $25^{\circ} \mathrm{C}-30^{\circ} \mathrm{C}$ ) to maintain the venous oxygen saturation between $65 \%$ and $75 \%$. If needed, conventional hemofiltration was used or extra PRBCs were added during the rewarming period of CPB to meet the oxygen consumption, and extra fluid was removed with modified hemofiltration to increase the hematocrit value to 0.32 to 0.35 after discontinuation of CPB. After discontinuation of CPB and modified hemofiltration, anticoagulation was reversed with protamine sulfate. Hypothermic myocardial protection was provided by aortic crossclamping and antegrade infusion of ice-cold cardioplegic solution, as described above, in a single dose of $20 \mathrm{~mL} / \mathrm{kg}$ over 2 minutes. The cardioplegic solution was aspirated by means of vigorous suction at the coronary sinus to prevent its return into the CPB circuit.

\section{Postoperative Management}

Routine continuous postoperative monitoring included surface electrocardiography, transcutaneous pulse oximetry, and systemic arterial pressure measurement. Inotropic, chronotropic, and afterload-reducing agents were used as clinically indicated. Volume infusions (usually PRBCs or 5\% albumin) were administered to maintain adequate filling pressures with systolic perfusion pressures. Diuretics (usually furosemide, $1-2 \mathrm{mg} \cdot \mathrm{kg}^{-1}$ per dose) 
were begun on the first postoperative morning or earlier if the patient was oliguric $\left(<1 \mathrm{~cm}^{3} \cdot \mathrm{kg}^{-1} \cdot \mathrm{h}^{-1}\right)$.

\section{Measurement of Serum Cardiac Troponin I Concentrations}

For each patient, six 2-mL blood samples were taken: at the induction of anesthesia and again 1, 3, 6, 12, and 24 hours after arrival in the intensive care unit (ICU). The blood was transferred into dry glass tubes and stored at $4^{\circ} \mathrm{C}$ to $8^{\circ} \mathrm{C}$ for clot formation before centrifugation. Serum separated after centrifugation was frozen at $-70^{\circ} \mathrm{C}$ until assay. The serum cardiac troponin I (cTnI) concentration was measured in the Department of Clinical Laboratory of our hospital in duplicate with an Access AccuTnI assay (Beckman Coulter, Fullerton, Calif) system by individuals unaware of the group allocation.

\section{Data Collection}

Preoperative and postoperative data were collected prospectively by the study team from the day of surgical intervention until hospital discharge. The preoperative data included age, sex, and body weight. The operative data include $\mathrm{CPB}$ time; aortic crossclamp time; total volume of cardioplegia; lowest temperature during $\mathrm{CPB}$; hematocrit value before the operation, during $\mathrm{CPB}$, and at the end of the operation; total volume of fluid output (ultrafiltration plus urine volume) during the operation; and hemodynamic parameters, including blood pressure data before the start of CPB, after the discontinuation of CPB, and at the end of modified ultrafiltration (MUF). The postoperative data included the number of hours of mechanical ventilation in the ICU, the number of days in the ICU, total volume of blood transfusion, total volume of chest drainage, and length of hospitalization after the operation. Any complications after the operation were also recorded. Serial data, such as serum cTnI concentration at different time points, were measured as described above. The inotrope scores $^{6,7,8}$ at different time points in the ICU were calculated as dopamine $(\times 1)$ plus dobutamine $(\times 1)$ plus amrinone $(\times 1)$ plus milrinone $(\times 15)$ plus epinephrine $(\times 100)$ plus norepinephrine $(\times 100)$ plus isoprenaline $(\times 100)$.

\section{Statistical Analyses}

All continuous variables are expressed as means \pm standard error of the mean, whereas discrete variables are presented as frequencies and percentages. Analyses of categorical variables were performed with the $\chi^{2}$ test. Analysis of continuous variables was performed with a 2-way analysis of variance, and multiple comparisons were made with post hoc least-significant-difference comparisons.

\section{RESULTS \\ Overall Clinical Results and Safety Evaluation}

All 3 cardioplegic solutions quickly arrested hearts within 2 minutes. There were no significant mechanical or electrical activities during the intracardiac operative period for all 3 groups. All the patients resumed spontaneous rhythm on aortic crossclamp removal, and there was no temporary pacing needed for any hearts. There were no deaths; no dialysis was necessitated because of renal failure, no cerebral impairment occurred, and no mediastinal reexploration was required because of postoperative bleeding in any of the 3 groups. There was a 6-month-old girl with ventricular septal defect and pulmonary hypertension in the MPAL group who underwent cardiopulmonary resuscitation and reintubation at the third postoperative day caused by vomiting and pulmonary aspiration. The resuscitation was successful, and the intubation was removed on the 15 th postoperative day. She was discharged on the 24th postoperative day without any complications.

\section{Comparison of Operative and Postoperative Parameters}

As indicated in Table 2, the preoperative and operative parameters among the 3 groups were comparable with regard to aortic crossclamp time, CPB time, cardioplegia volume, lowest body temperature during $\mathrm{CPB}$, hematocrit value (before the operation, during $\mathrm{CPB}$, and at the end of operation), and fluid output during the operation.

The total mediastinal drainage volume and the first mechanical ventilation time were comparable among the 3 groups; the reintubation time for the child in the MPAL group was not included in the statistical analysis. The ICU times of the 3 groups were comparable $(P=.053)$. The postoperative hospital times of the 3 groups were comparable $(P=.304)$.

\section{Hemodynamic Changes During the Operation}

Systolic and diastolic arterial pressures were recorded; pulse pressures were calculated according to the following

TABLE 2. The operative and postoperative parameters of the 3 groups $(m e a n \pm S E M)$

\begin{tabular}{|c|c|c|c|c|}
\hline & HP group $(n=46)$ & HPAL group $(n=44)$ & MPAL group $(n=44)$ & $P$ value \\
\hline Crossclamp time, $\min$ & $40.6 \pm 3.0$ & $37.9 \pm 2.7$ & $38.8 \pm 3.0$ & .797 \\
\hline $\mathrm{CPB}$ time, $\min$ & $66.7 \pm 3.6$ & $66.9 \pm 3.3$ & $66.9 \pm 3.8$ & .999 \\
\hline Volume of cardioplegia, $\mathrm{mL}$ & $213 \pm 12$ & $214 \pm 18$ & $206 \pm 15$ & .921 \\
\hline Lowest body temperature, ${ }^{\circ} \mathrm{C}$ & $29.8 \pm 0.2$ & $30.0 \pm 0.2$ & $29.9 \pm 0.2$ & .790 \\
\hline \multicolumn{5}{|l|}{ Hematocrit, $\%$} \\
\hline Preoperative & $36.4 \pm 0.5$ & $36.8 \pm 0.4$ & $36.5 \pm 0.5$ & .841 \\
\hline During CPB & $24.9 \pm 0.6$ & $23.9 \pm 0.4$ & $24.6 \pm 0.4$ & .347 \\
\hline End of operation & $35.5 \pm 0.7$ & $36.0 \pm 0.3$ & $35.6 \pm 0.8$ & .807 \\
\hline Fluid output at end of operation, $\mathrm{mL}$ & $483 \pm 40$ & $460 \pm 39$ & $465 \pm 22$ & .880 \\
\hline Mechanical ventilation time, $\mathrm{h}$ & $10.6 \pm 1.5$ & $9.3 \pm 0.7$ & $11.3 \pm 1.0$ & .452 \\
\hline Total mediastinal drainage, $\mathrm{mL}$ & $103 \pm 9$ & $87 \pm 7$ & $119 \pm 14$ & .111 \\
\hline ICU time, $\mathrm{d}$ & $2.5 \pm 0.1$ & $2.4 \pm 0.2$ & $2.7 \pm 0.4$ & .053 \\
\hline Postoperative hospital time, $\mathrm{d}$ & $12.7 \pm 1.1$ & $11.8 \pm 0.6$ & $11.1 \pm 1.4$ & .304 \\
\hline
\end{tabular}

$S E M$, Standard error of the mean; $H P$, high potassium; $H P A L$, high potassium adenosine-lidocaine; $M P A L$, moderate-potassium adenosine-lidocaine; $C P B$, cardiopulmonary bypass; $I C U$, intensive care unit. 
equation: Pulse pressure $=$ Systolic pressure-Diastolic pressure.

As indicated in Table 3, these 3 parameters changed in the same fashion, decreasing at the end of CPB and then increasing at the end of MUF. They were similar before the start of the CPB among the 3 groups. At the end of CPB, the systolic and pulse pressures of the MPAL group were significantly increased compared with the respective values of the HP group $(68 \pm 2.1$ vs $62 \pm 1.5 \mathrm{~mm} \mathrm{Hg}[P=.013]$ and $29 \pm$ 1.5 vs $25 \pm 0.9 \mathrm{~mm} \mathrm{Hg}[P=.029]$, respectively). At the end of MUF, the systolic and pulse pressures of the MPAL group were significantly increased compared with the respective values of the HP group $(81 \pm 1.7$ vs $73 \pm$ $1.6 \mathrm{~mm} \mathrm{Hg}[P=.001]$ and $36 \pm 0.9$ vs $29 \pm 1.1 \mathrm{~mm} \mathrm{Hg}$ $[P=.000]$, respectively). At the end of MUF, the systolic pressure of the HPAL group was increased compared with that of the HP group $(78 \pm 1.7$ vs $73 \pm 1.6 \mathrm{~mm} \mathrm{Hg}[P=$ $.030])$, but the differences in pulse pressures between these 2 groups did not reach a statistically significant level (32 \pm 1.1 vs $29 \pm 1.1 \mathrm{~mm} \mathrm{Hg}[P=.092])$.

\section{Serum cTnI Release}

In the 3 groups the concentrations of serum cTnI before the operation were at similarly low levels. They surged to high levels after the removal of the aortic crossclamp, reached their highest level 3 hours after reperfusion, and then decreased in the same fashion but did not return to the preoperative baseline at 24 hours after removal of the aortic crossclamp (Table 4). However, at the time points from 1 to 12 hours after reperfusion, levels of serum cTnI were significantly decreased in the MPAL group compared with those in the HP and HPAL groups.

\section{Inotrope Score}

We evaluated inotropic drug use according to the inotrope scoring method previously used by our group, and there were no significant differences among the 3 groups. It seemed that the inotrope scores in the HP group were higher than those in the HPAL and MPAL groups at the time points of $1,3,6,12$, and 24 hours after ICU arrival, but analysis showed that the differences did not reach a statistically significant level (Table 5).
TABLE 3. Hemodynamic changes during surgical intervention in the 3 groups (mean $\pm \mathrm{SEM})$

\begin{tabular}{llccc}
\hline & $\begin{array}{c}\text { HP group } \\
(\mathbf{n}=\mathbf{4 6})\end{array}$ & $\begin{array}{c}\text { HPAL group } \\
(\mathbf{n}=\mathbf{4 4})\end{array}$ & $\begin{array}{c}\text { MPAL group } \\
(\mathbf{n}=\mathbf{4 4})\end{array}$ & $\begin{array}{c}\boldsymbol{P} \\
\text { value }\end{array}$ \\
\hline $\begin{array}{c}\text { Before CPB } \\
\text { Systolic pressure, }\end{array}$ & $80 \pm 2.2$ & $81 \pm 2.2$ & $77 \pm 2.0$ & .370 \\
$\quad$ mm Hg \\
$\begin{array}{c}\text { Diastolic pressure, } \\
\text { mm Hg }\end{array}$ & $48 \pm 1.5$ & $49 \pm 1.7$ & $47 \pm 1.6$ & .764 \\
$\begin{array}{c}\text { Pulse pressure, } \\
\text { mm Hg }\end{array}$ & $32 \pm 1.6$ & $33 \pm 1.0$ & $30 \pm 1.4$ & .407 \\
$\begin{array}{c}\text { After CPB } \\
\text { Systolic pressure, } \\
\text { mm Hg }\end{array}$ & $62 \pm 1.5$ & $65 \pm 1.6$ & $68 \pm 2.1^{*}$ & .034 \\
$\begin{array}{c}\text { Diastolic pressure, } \\
\text { mm Hg }\end{array}$ & $37 \pm 1.2$ & $39 \pm 1.1$ & $40 \pm 1.7$ & .370 \\
$\begin{array}{c}\text { Pulse pressure, } \\
\text { mm Hg }\end{array}$ & $25 \pm 0.9$ & $26 \pm 1.0$ & $29 \pm 1.5^{*}$ & .059 \\
$\begin{array}{c}\text { After MUF } \\
\text { Systolic pressure, } \\
\text { mm Hg }\end{array}$ & $73 \pm 1.6$ & $78 \pm 1.7^{*}$ & $81 \pm 1.7^{*}$ & .005 \\
$\begin{array}{c}\text { Diastolic pressure, } \\
\text { mm Hg }\end{array}$ & $44 \pm 1.4$ & $46 \pm 1.2$ & $45 \pm 1.7$ & .486 \\
$\begin{array}{c}\text { Pulse pressure, } \\
\text { mm Hg }\end{array}$ & $29 \pm 1.1$ & $32 \pm 1.1$ & $36 \pm 0.9^{*}$ & .000 \\
\hline
\end{tabular}

SEM, Standard error of the mean; $H P$, high potassium; $H P A L$, high potassium adenosine-lidocaine; $M P A L$, moderate-potassium adenosine-lidocaine; $C P B$, cardiopulmonary bypass; $M U F$, modified ultrafiltration. *Significantly increased compared with the respective value in the HP group.

\section{DISCUSSION}

\section{Safety and Effectiveness}

This clinical study compared the myocardial protective effects of different potassium concentrations during AL cardioplegia relative to classic high-potassium cardioplegia during hypothermia in pediatric patients with congenital heart defects. Because this was an explorative study, we enrolled patients with relatively simple heart defects that could be repaired without prolonged CPB time and heart arrest time. All 3 cardioplegic formulas arrested hearts quickly within 2 minutes. There were no significant mechanical or electrical activities during the intracardiac operative period in all 3 groups. There were no deaths, no dialyses necessitated by renal failure, no cerebral impairments, and no requirement for mediastinal reexploration caused by postoperative bleeding in the

TABLE 4. Serial perioperative serum cTnI concentrations (mean \pm SEM)

\begin{tabular}{|c|c|c|c|c|}
\hline & HP group $(n=46)$ & HPAL group $(n=44)$ & MPAL group $(n=44)$ & $P$ value \\
\hline Before the operation & $0.22 \pm 0.03$ & $0.17 \pm 0.03$ & $0.16 \pm 0.03$ & .262 \\
\hline One hour after reperfusion & $48.94 \pm 9.60$ & $28.86 \pm 2.70$ & $18.32 \pm 2.79 * \dagger$ & .002 \\
\hline Three hours after reperfusion & $53.46 \pm 9.41$ & $36.78 \pm 3.75$ & $25.76 \pm 3.47 * \dagger$ & .009 \\
\hline Six hours after reperfusion & $34.61 \pm 4.40$ & $36.21 \pm 3.80$ & $21.97 \pm 3.08 * \dagger$ & .018 \\
\hline Twelve hours post reperfusion & $29.84 \pm 3.99$ & $28.89 \pm 2.97$ & $18.56 \pm 2.60 * \dagger$ & .029 \\
\hline Twenty-four hours after reperfusion & $20.33 \pm 2.79$ & $19.59 \pm 2.29$ & $13.72 \pm 2.16$ & .116 \\
\hline
\end{tabular}

Values are presented in nanograms per milliliter. SEM, Standard error of the mean; HP, high-potassium; HPAL, high-potassium adenosine-lidocaine; $M P A L$, moderate-potassium adenosine-lidocaine. *Significantly decreased compared with the respective value in the HP group. $\dagger$ Significantly decreased compared with the respective value in the HPAL group. 
TABLE 5. Serial postoperative inotropic scale comparisons among the 3 groups (mean \pm SEM)

\begin{tabular}{lcccc}
\hline & $\begin{array}{c}\text { HP group } \\
(\mathbf{n}=\mathbf{4 6})\end{array}$ & $\begin{array}{c}\text { HPAL group } \\
(\mathbf{n}=\mathbf{4 4})\end{array}$ & $\begin{array}{c}\text { MPAL group } \\
(\mathbf{n}=\mathbf{4 4})\end{array}$ & $\begin{array}{r}\boldsymbol{P} \\
\text { value }\end{array}$ \\
\hline $\begin{array}{l}\text { One hour after ICU } \\
\text { arrival }\end{array}$ & $3.8 \pm 0.5$ & $2.7 \pm 0.4$ & $2.6 \pm 0.2$ & .053 \\
$\begin{array}{c}\text { Three hours after ICU } \\
\quad \text { arrival }\end{array}$ & $3.8 \pm 0.5$ & $2.8 \pm 0.4$ & $2.7 \pm 0.2$ & .085 \\
$\begin{array}{c}\text { Six hours after ICU } \\
\text { arrival }\end{array}$ & $3.8 \pm 0.5$ & $2.8 \pm 0.5$ & $2.7 \pm 0.2$ & .103 \\
$\begin{array}{c}\text { Twelve hours after } \\
\quad \text { ICU arrival }\end{array}$ & $3.7 \pm 0.5$ & $2.8 \pm 0.5$ & $2.7 \pm 0.2$ & .145 \\
$\begin{array}{c}\text { Twenty-four hours } \\
\text { after ICU arrival }\end{array}$ & $3.3 \pm 0.4$ & $2.7 \pm 0.4$ & $2.3 \pm 0.3$ & .194 \\
$\begin{array}{c}\text { Forty-eight hours after } \\
\quad 2.0 \pm 0.4\end{array}$ & $2.5 \pm 0.4$ & $1.4 \pm 0.3$ & .081 \\
\hline ICU & & & &
\end{tabular}

ICU arrival

SEM, Standard error of the mean; $H P$, high-potassium; $H P A L$, high-potassium adenosine-lidocaine; $M P A L$, moderate-potassium adenosine-lidocaine; $I C U$, intensive care unit.

3 groups. We conclude that the clinical use of HPAL and MPAL cardioplegia is safe and effective.

\section{Correlation Between Cell Membrane Potential and Potassium Concentration in Cardioplegia}

The cell membrane potential (VM in millivolts) can be calculated from the Nernstian distribution of $\mathrm{K}^{+}$ions between the extracellular and intracellular phases as follows ${ }^{4}$ :

$$
V_{\mathrm{M}}=E_{k^{+}} \frac{R T}{z_{K^{+}} F} \times \ln \frac{\left[K^{+}\right]_{\text {OUT }}}{\left[K^{+}\right]_{I N}},
$$

where $\mathrm{R}$ is the universal gas constant $\left(8.31 \mathrm{~J}^{2} \% 2219 \mathrm{~mol}^{-1}\right.$. $\left.\mathrm{K}^{-1}\right), \mathrm{F}$ is Faraday's constant $\left(96.49 \mathrm{KJ} \cdot \mathrm{mol}^{-1} \cdot \mathrm{V}^{-1}\right)$, $\mathrm{T}$ is absolute temperature $(311.15 \mathrm{~K}), \mathrm{z}$ is the valence of potassium ion $(+1)$, and $\left[\mathrm{K}^{+}\right]_{\mathrm{IN}}$ and $\left[\mathrm{K}^{+}\right]_{\text {OUT }}$ are the intracellular and extracellular concentrations of $\mathrm{K}^{+}$ions in moles per liter, respectively. $\left[\mathrm{K}^{+}\right]_{\mathrm{IN}}$ was estimated to be a constant value of about 88 to $89 \mathrm{mmol} / \mathrm{L}$, and it was assumed that $\left[\mathrm{K}^{+}\right]_{\text {Out }}$ was equal to the potassium concentration in the HP and HPAL cardioplegic formulas $\left(20 \mathrm{mmol} / \mathrm{L} \mathrm{K}^{+}\right)$and the MPAL cardioplegic formula $\left(10 \mathrm{mmol} / \mathrm{L} \mathrm{K}^{+}\right)$. The cell membrane potential was approximately $-46 \mathrm{mV}$ when the HP and HPAL cardioplegic solutions were used and approximately -67 $\mathrm{mV}$ when the MPAL cardioplegic solution was used. Our results support the hypothesis that a less depolarized cell membrane during cardioplegic arrest is related to better myocardial protection and less reperfusion injury. This could be reflected by the better hemodynamic features during the operation and the decreased cTnI release during the early postreperfusion period in the MPAL group.

\section{Mechanisms for MPAL Cardioplegia's Superiority Over HP Cardioplegia}

The mechanisms for MPAL cardioplegia's superiority over HP cardioplegia were not investigated in the present study but have previously been extensively discussed by Dobson. ${ }^{6}$ We summarize the main points as follows.

First, combined use of adenosine and lidocaine is related to better preservation of adenosine triphosphate, phosphocreatine, and glycogen stores and maintenance of a high cytosolic phosphorylation ratio during arrest, ischemia, and reperfusion.

Second, adenosine activates the A1 receptor subtype to exhibit its negative chronotropy, negative dromotropy, and negative inotropy, which contribute to arresting the heart. Furthermore, A1 receptor activation has been linked to the opening of the sarcolemmal adenosine triphosphate-sensitive $\mathrm{K}^{+}$channel, stabilization of mitochondria mitochondrial permeability transition pore, and inhibition of the stimulatory effects of catecholamines.

Third, Lidocaine can block cardiomyocyte fast $\mathrm{Na}^{+}$channels and effectively clamp the cell membrane near its resting membrane potential. Because fewer ion channels or pumps are activated at polarized potentials, the drug might reduce energy-sparing effects.

Fourth, because of fast $\mathrm{Na}^{+}$-channel blockade, the lidocaine and adenosine combination might further reduce $\mathrm{Na}^{+}$ and $\mathrm{Ca}^{++}$loading.

Fifth, superior arrest and protection might also relate to the coronary vasodilatory properties of adenosine, lidocaine, and low potassium concentration, which result in reduced coronary vascular resistance and greater delivery of cardioplegia. This had been confirmed by the study of Dobson. $^{4}$

Sixth, concentrations of potassium of greater than 15 $\mathrm{mmol} / \mathrm{L}$ have been linked to left ventricular dysfunction and endothelial damage, and these deleterious effects are concentration dependent. Our results support these experimental studies and show that MPAL cardioplegia is linked with better hemodynamic features, including higher systolic pressures and pulse pressures at the end of CPB and MUF compared with the HP and HPAL groups.

\section{Limitations of the Study}

One of the limitations of this study was that the patients included in the study were all committed with simple congenital heart defects without cyanosis, and therefore the significance of the results might be very limited. Another limitation of this study was that we used systolic and pulse pressures to evaluate the hemodynamic performances of different groups. Because the pressure measurements were load dependent, this somewhat impaired their significance as perfect parameters of heart functions during the operation. Considering this was a controlled, blind, and randomized study, the pressure measurements still had some values to reflect the hemodynamic differences. The most important limitation of this study was that the cardioplegic formula we used was not a normokalemic one, which is somewhat different from Dobson's studies. 
A normokalemic cardioplegic solution might be better than the MPAL solution we used here, and the newest evidence from Dobson's laboratory ${ }^{9}$ showed that normokalemic AL cardioplegia could be delivered intermittently or continuously with similar functional recoveries after a 40 - or 60minute arrest at $33^{\circ} \mathrm{C}$ in an isolated, perfused rat heart model. For safety reasons, we did not try the normal-potassium AL formula in a clinical setting. Corvera and associates ${ }^{5}$ demonstrated that intermittent polarized arrest with warm or cold AL blood cardioplegia provided the same degree of myocardial protection as intermittent hypothermic $\mathrm{K}^{+}$-blood cardioplegia in a canine CPB model, but the AL solution did not show any superiority to traditional hyperkalemic cardioplegia. Whether normal-potassium AL cardioplegia is as safe and effective as MPAL cardioplegia in a clinical setting requires more experimental investigation.

\section{CONCLUSION}

The combined use of adenosine and lidocaine in a moderate-potassium cardioplegic formula resulted in better myocardial protection.
We thank Ying Yang for her excellent assistance in cardiomyocyte membrane potential calculation.

\section{References}

1. Chambers DJ, Hearse DJ. Cardioplegia and surgical ischaemia. In: Sperelakis N Kurachi Y, Terzic A, Cohen MV, eds. Heart physiology and pathophysiology. San Diego: Academic Press; 2001:887-926.

2. Jayawant AM, Stephenson ER Jr, Matte GS, et al. Potassium channel opener cardioplegia is superior to St. Thomas' solution in the intact animal. Ann Thorac Surg. 1999;68:67-74.

3. Chambers DJ. Polarization and myocardial protection. Curr Opin Cardiol. 1999; 14:495-500.

4. Dobson GP, Jones MW. Adenosine and lidocaine: A new concept in nondepolarizing surgical myocardial arrest, Protection, and preservation. J Thorac Cardiovasc Surg. 2004;127:794-805.

5. Corvera JS, Kin H, Dobson GP, et al. Polarized arrest with warm or cold adenosine/ lidocaine blood cardioplegia is equivalent to hypothermic potassium blood cardioplegia. J Thorac Cardiovasc Surg. 2005;129:599-606.

6. Shore S, Nelson DP, Pearl JM, et al. Usefulness of corticosteroid therapy in decreasing epinephrine requirements in critically ill infants with congenital heart disease. Am J Cardiol. 2001;88:591-4.

7. Jin ZX, Zhou JJ, Xin M, et al. Postconditioning the human heart with adenosine in heart valve replacement surgery. Ann Thorac Surg. 2007;83:2066-72.

8. Wernovsky G, Wypij D, Jonas RA, et al. Postoperative course and hemodynamic profile after the arterial switch operation in neonates and infants. A comparison of lowflow cardiopulmonary bypass and circulatory arrest. Circulation. 1995;92:2226-35.

9. Sloots KL, Vinten-Johansen J, Dobson GP. Warm nondepolarizing adenosine and lidocaine cardioplegia: continuous versus intermittent delivery. $J$ Thorac Cardiovasc Surg. 2007; 133:1171-8. 